\title{
Scaling properties of rainfall and desert dust in the Canary Islands
}

\author{
I. Peñate ${ }^{1}$, J. M. Martín-González ${ }^{2}$, G. Rodríguez ${ }^{2}$, and A. Cianca ${ }^{2}$ \\ ${ }^{1}$ Agencia Estatal de Meteorología, Delegación Territorial en Canarias, C/ Historiador Fernando de Armas, 12, 35017, \\ Las Palmas de Gran Canaria, Spain \\ ${ }^{2}$ Departamento de Física, Universidad de Las Palmas de Gran Canaria, 35017, Las Palmas de Gran Canaria, Spain
}

Correspondence to: I. Peñate (ipenated@ aemet.es)

Received: 20 July 2013 - Revised: 8 October 2013 - Accepted: 23 October 2013 - Published: 9 December 2013

\begin{abstract}
Precipitation and desert dust event occurrence time series measured in the Canary Islands region are examined with the primary intention of exploring their scaling characteristics as well as their spatial variability in terms of the island's topography and geographical orientation. In particular, the desert dust intrusion regime in the islands is studied in terms of its relationship with visibility. Analysis of dust and rainfall events over the archipelago exhibits distributions in time that obey power laws. Results show that the rain process presents a high clustering and irregular pattern on short timescales and a more scattered structure for long ones. In contrast, dustiness presents a more uniform and dense structure and, consequently, a more persistent behaviour on short timescales. It was observed that the fractal dimension of rainfall events shows an important spatial variability, which increases with altitude, as well as towards northern latitudes and western longitudes.
\end{abstract}

\section{Introduction}

Life on Earth critically depends on freshwater availability. In particular, human life, settlement, and any of their activities are restricted by the existence of such a vital resource. This fact is particularly evident in desert, arid, and semi-arid zones, where prolonged droughts are commonly related to health problems, soil erosion and massive population displacements. Hence, mankind largely depends upon precipitation, the primary mechanism transporting water from the atmosphere to the planet surface, as a part of the water cycle, and a driving agent of many other processes. Consequently, temporal and spatial variability of precipitation are issues of general concern. Thus, positive or negative anomalies in precipitation regimes have severe impacts on freshwater avail- ability for consumption, agriculture, terrain stability, desertification processes, and so on (e.g. Potter and Colman, 2003). Another aspect of huge importance for human life and the environment is the quality of the surrounding air. In this sense, air composition normally includes some fraction of solid material, which generally results from anthropogenic air pollution, biomass burning, or soil erosion by wind. In particular, mineral dust from desert, arid, and semi-arid regions can be eroded and suspended in the air, giving rise to dust storms, also referred to as desert dust outbreaks or intrusions. Dust can be transported by wind over large distances on Earth's surface and, as a consequence, its effects can be felt in regions far away from the dust sources. Suspended, transported and deposited mineral dust has a broad range of important socioeconomic and environmental implications. In general, dust storms reduce visibility and disrupt daily life and economic activities.

Desert aeolian emissions play an important role in regional weather and climate (Sassen et al., 2003). For instance, the impact of dust storms on the Earth-atmosphere radiative system has been studied by some authors (Slingo et al., 2006; Heinold et al., 2007; Kaufman et al., 2002; Sassen et al., 2003). The aerosol effects on precipitation formation and distribution have also been considered (Lynn et al., 2007). Others interesting aspects are that mineral aerosols exert an important influence over the distribution of soil nutrients (Mahowald et al., 2005; Yoon et al., 2007), induce changes in soil characteristics (McTainsh and Strong, 2007) and cause adverse effects on human health (Boreson et al., 2004; Fisher et al., 2000; Goudie, 2009; De Longueville et al., 2010, 2012, 2013). Additionally, large concentrations of aeolian emissions could lead to problems in transport operations (Baddock et al., 2013). Mineral dust deposition on the ocean surface represents an input of micronutrients and, as 
a consequence, partially controls the productivity of marine ecosystems (Shi et al., 2011). A detailed list of environmental consequences and hazards to human population caused by dust storms, as well as an excellent review of causes and effects of dust storms, can be found in Goudie and Middleton (2006).

Previous comments are of particular concern for the $\mathrm{Ca}$ naries, due to their low pluviometry and proximity of the Sahara, which produces more than half of the yearly global mineral dust (De Longueville et al., 2010). The hydraulic resources directly derived from rainfall in the archipelago are scarce. Hydric conditions have worsened with demographic increase and tourism development, giving rise to the aquifers' overexploitation (Custodio, 2002), but have been partially alleviated through the construction of reservoirs and by a great development in seawater desalination technology (Veza, 2001). On the other hand, desert dust intrusions are a common phenomenon in the archipelago, which is located along one of the three major Sahara dust pathways and within one of the North Atlantic Ocean surface parcels with higher annual dust deposition rates (Goudie and Middleton, 2001). Furthermore, two source regions of dust (Sahelian and Sahara) related to different atmospheric pathways of the desert mineral dust affect the Canary Islands (Bergametti et al., 1989). The most important aerosol invasions over the area of the Canaries respond to a long-range transport pattern. Aeolian emissions stemming from the Sahara, the largest dust source in the world, can reduce the visibility over the islands to a few kilometres (Díaz et al., 2001). As a consequence, the following impacts on the islands concerning desert dust intrusions have been reported: air traffic managing (Criado and Dorta, 2002), changes in soil properties (Suchodoletz, 2013) and health (Juliá-Serdá et al., 2005; Sánchez-Lerma et al., 2009).

In brief, rain events, droughts, and desert dust outbreaks are natural phenomena, related to the atmospheric dynamics, which under some conditions can turn into natural catastrophes (De et al., 2004). Owing to their highly complex nature, these processes are not fully understood and deserve further study. The Canary Islands constitute an isolated spot poorly studied from a climatic point of view (e.g. Puyol, et al., 2002). In this sense, de Lima and de Lima (2009) properly pointed out that precipitation studies on the islands are scarce and based on large temporal scales. Moreover, a recent review (De Logueville et al., 2013) on desert dust impacts on human health stresses the need to carry out studies on Saharan dust impact in western Africa, where dust events are more frequent and intense than anywhere else.

Nevertheless, the atmosphere is a highly non-linear and complex dynamical system. Hence, as with many others meteorological phenomena, rainfall is characterised by very complex dynamics exhibiting wide variability over a broad range of time and space scales. Similarly, the presence of desert dust in the atmosphere and its variability depends on an intricate combination of processes and interactions. Tur- bulent wind action over source areas and favourable synoptic conditions to transport dust to the interest area are some of them (Liu et al., 2004). The turbulent nature of atmospheric flows could play a relevant role in the physical process behind rainfall and desert dust. Some authors have shown that turbulence is related to some features such as solar flare activity (Boffetta et al., 1999).

Additionally, rainfall variability and dust storm occurrence are mutually related to complex and not yet well understood mechanisms. Thus, rainfall is one of the most important factors controlling the occurrence of mineral dust erosion from soils. Rainfall in the source area reduces dust erosion, while intense erosion is commonly related to episodes of drought (Prospero and Lamb, 2003). On the other hand, the presence of desert dust in the atmosphere has an effect on rainfall in a still not well known way. Several papers provide no definitive and even contradictory results (e.g. Levin and Cotton, 2009) about these issues.

Because of the high complexity of atmospheric processes, conventional statistical methods have proved to be quite inefficient to describe the statistical structure of phenomena such as rainfall over a wide range of scales. However, it has been shown that many complex processes occurring in Earth's atmosphere exhibit fractal or power law scaling (e.g. Dickman, 2004), particularly rainfall occurrences (Mazzarella and Diodato, 2002). That is, statistical properties of a given process are similarly related to each other over a wide range of scales. Thus, exploration of invariance properties across scales offers an alternative approach to quantify the variability of rainfall and desert dust emission processes. Considering the need to improve knowledge on the variability of rainfall and desert aerosol outbreaks in the Canary Islands and the intrinsic complexity of these phenomena, the main goal of this study is to contribute to a better understanding of their temporal scaling properties, as well as their spatial variability. Specifically, the study intends to explore the desert dust intrusion intensity and duration, at low atmospheric levels, in terms of the horizontal visibility reduction.

The rest of the paper is organised as follows. The next section presents a brief description of topographic and climatic features of the archipelago, as well as the main characteristics of the data sets examined in the study. Data analysis methods used to explore scaling properties in rainfall and desert dust observations are described in Sect. 3. Section 4 contains results derived from the analysis of experimental data and their discussion. Finally, Sect. 5 outlines the main conclusions of the study.

\section{Study area and data sets}

\subsection{Study area}

The Canary archipelago, constituted by seven inhabited islands (Lanzarote, Fuerteventura, Gran Canaria, Tenerife, 
La Palma, La Gomera, and El Hierro), is a Spanish autonomous community and the outermost region of the European Union. It is located in the Atlantic Ocean, bounded by $27^{\circ} 37^{\prime}$ and $29^{\circ} 30^{\prime} \mathrm{N}$ latitudes and $13^{\circ} 30^{\prime}$ and $18^{\circ} 10^{\prime} \mathrm{W}$ longitudes (Fig. 1). Generated as the result of volcanic activity on the African continental shelf, it forms a chain with a roughly linear arrangement extending about $500 \mathrm{~km}$ in the longitudinal direction. Its eastern edge lies only $100 \mathrm{~km}$ from the Saharan coast. The orography and topography of the islands are highly variable, with sharp differences between and within islands. Elevation changes from a maximum height of about $3718 \mathrm{~m}$ a.s.l., in Tenerife, to elevations rarely above $600 \mathrm{~m}$ in the eastern islands (Lanzarote and Fuerteventura). La Palma, Gran Canaria, El Hierro and La Gomera, also exhibit high elevations, close to 2400, 1950, 1500 , and $1490 \mathrm{~m}$, respectively. In general, the islands' orography is very rugged, except in the flat eastern islands.

This densely populated oceanic archipelago has a combination of subtropical, semi-arid and semi-humid conditions (Sperling et al., 2004) with strong orographic, topographic, meteorological and ecological contrasts.

Due to their location in the Atlantic subtropical belt and being dominated almost all year by the Azores High, which prevents transient disturbances as Atlantic lows, the typical weather in the Canaries can be considered stable and dry. The islands are exposed to the predominant trade winds, blowing over the Atlantic from the northeast for almost the whole year and driving one of the major coastal upwelling ecosystems in the world along the NW African coast (Fernandopullé, 1976). Their oceanic position, within an area affected by both coastal upwelling and Saharan mineral dust eolian inputs, strongly influences their climate, which is characterised by a low annual thermal oscillation ranging from $18^{\circ} \mathrm{C}$ during winter to $24^{\circ} \mathrm{C}$ in summer and influenced mainly by cloudiness, altitude and orientation (Font-Tullot, 1956; Martín et al., 2012). The proximity to the Sahara converts the archipelago into a very complex scenario. Between approximately 700 and $1500 \mathrm{~m}$ a subsidence inversion is often present. Above the inversion layer, the air is dry and clear. The existence of two astronomical observatories, El Roque de los Muchachos (La Palma) and El Teide (Tenerife), reveals the presence of clear skies with excellent air quality. Below the inversion layer, the presence of a fresh and humid boundary layer explains the marked contrast between the windward side with green valleys in the north and the leeward side of the islands with sandy beaches. Vegetation zones can be classified into humid and semi-arid types (Juan et al., 2000). When prevailing trade winds reach the higher islands, moisture is condensed, bringing cloudiness, humidity and sometimes rain to the northern sectors. Hence, northern locations are generally dull, wet and cloudy, while southern ones are characterised by dry clear days with sunshine.

The main feature of the rainfall regime in the Canaries is its irregularity. The location of the islands, far from the belt of low pressures in the medium latitudes, explains the low rate

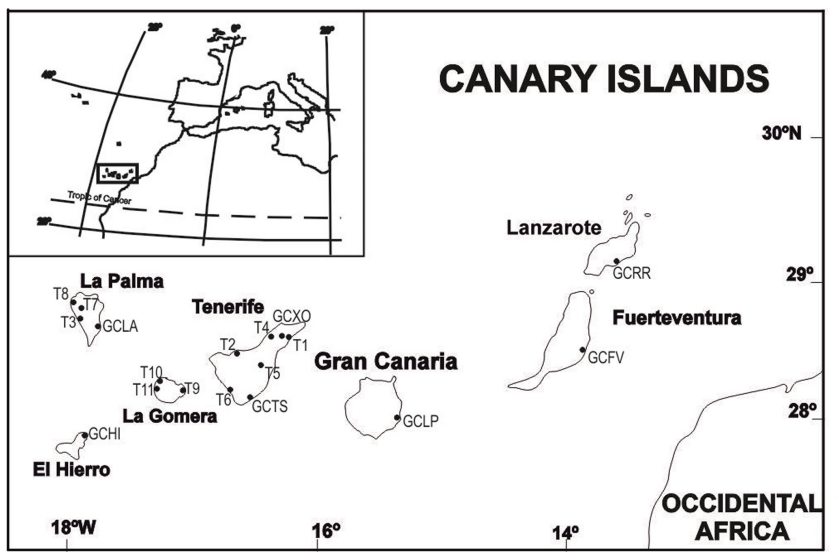

Fig. 1. Geographic location of the Canary Islands and recording stations used in the study. The airport is the only station included for Gran Canaria in this figure, the others are shown in Fig. 2.

of precipitation throughout the islands. However, the combined effect of the trade winds and the abrupt relief makes some places of these islands much wetter than the normal pattern at this latitude. The island's averaged precipitation regimes show a strong seasonality with maximum monthly rainfall during autumn and winter and dry or rainless months in spring and summer.

The relief is one of the critical variables controlling the local rainfall distribution. In general, precipitation increases across the archipelago from east to west. Frontal tails associated with surface disturbances affect predominately the western and higher islands, which are much wetter. Conversely, the eastern islands are characterised by dry and stable meteorological conditions almost all year round and are quite arid (García-Herrera et al., 2001, 2003). The key role played by the topographic and orographic complexity of the islands is noteworthy. Predominant trade winds interact with the relief of the islands to generate mesoscale and microscale meteorological phenomena, leading to a large variability of microclimates. As result, the islands show a great biodiversity characterised by a large variety of species classified as tropical, subtropical, arid, semi-arid or Mediterranean (Arteaga et al., 2009; Zachow et al., 2008) and containing a great proportion of endemic ones. Among other important factors, the cold Canary Current is responsible for inducing atmospheric stability and, therefore, reduces the probability of development of subtropical systems and the occurrence of heavy winds or rainfall associated with them. Their almost latitudinal disposition and abrupt topography induce perturbations in the Canary Current and North Atlantic trade wind persistent flow, in which they are immersed.

In conclusion, the Canary Islands constitute a unique and highly complex environment to explore space and time properties of processes related to the atmospheric dynamics. 


\subsection{Data sets}

With reference to the previous comments, considerable spatial non-uniform rainfall and desert dust events are common in the study region. Hence, to take into account this spatial heterogeneity, data from various representative measurement points have been used. Rainfall and dust intrusion time series have been extracted from archives provided by Aemet (National Meteorological Service of Spain). Particularly, METeorological Aerodrome Reports (METARs) from three aerodromes of reference have been used. Such reports contain encoded information on atmospheric parameters and are made by trained certified weather observers who review and encode the observations. This procedure is developed following a protocol regulated by the World Meteorological Organization (WMO, 1995), in consort with the International Civil Aviation Organization (ICAO), and using a general global standard format. Data on Saharan dust levels are obtained by using a standard scale of visibility. Sahara dust can be distinguished from other causes by means of several features such as its colour, relative humidity, or visibility reduction.

The parameters extracted from METARs to be used in this study are visibility $(\mathrm{km})$, rainfall $\left(\mathrm{mm} \mathrm{m}^{-2}\right)$, wind direction (angular degrees) and wind speed $\left(\mathrm{kmh}^{-1}\right)$. The visibility is defined as the maximum distance that a black object of suitable dimensions can be seen near the horizon (Wauben, 2003). The observations of visibility used in this study were determined by a human observer using several landmarks. Special attention is paid to this parameter since low visibility could have disastrous impacts on air traffic. A considerable amount of research has looked into the relationship between visibility and aerosol properties or concentration (e.g. Dialmeida, 1986; Ben Mohamed et al., 1992; Bäumer et al., 2008). It is therefore reasonable to use visibility measurements as a proxy to explore desert dust events.

A very important advantage provided for this study, in spite of the intrinsic uncertainties of this traditional measurement procedure, is the availability of long-term horizontal visibility observations, from which intensity and duration of dust events can be inferred.

As a criterion for this work, a dust event duration has been defined as the number of dusty days, considering a day dusty when during a $24 \mathrm{~h}$ period a dust observation with visibility equal to, or lower than, $8 \mathrm{~km}$ is reported. The intensity of the dust event is estimated by the minor visibility recorded. For the selection of dust events, visibility data were considered only if the METAR included one of the following phenomena: haze (HZ), widespread dust in suspension in the air (DU), drifting dust raised by wind at or near the station at the time of observation (DRDU), dust storm (DS) or blowing dust (BLDU). Moreover, a rainfall event was considered when some of these descriptors were included in the METAR: RA (rain), SHRA (shower), TS (thunder storm) or DZ (drizzle).
Aerodromes chosen as reference are those from Gran Canaria (GCLP), Fuerteventura (GCFV) and La Palma (GCLA) (Fig. 1). These weather stations were selected based on availability of long data sets and representativeness. Gran Canaria airport, located at $27.93^{\circ} \mathrm{N}$ and $15.39^{\circ} \mathrm{W}$, with an elevation of $24 \mathrm{~m}$, an international high density traffic airport operational $24 \mathrm{~h}$ a day provides a good quality METARsbased data set. Fuerteventura airport situated at $28.45^{\circ} \mathrm{N}$ and $13.86^{\circ} \mathrm{W}$, with an elevation of $26 \mathrm{~m}$ and placed at the eastern edge of the archipelago, gives appropriate measurements of dust incursions affecting the islands, due to its proximity to the Sahara. Finally, La Palma airport, in the western side, sited at $28.62^{\circ} \mathrm{N}$ and $17.76^{\circ} \mathrm{W}$ at $33 \mathrm{~m}$ a.s.l. was also selected being affected by high precipitation when Atlantic lows influence the archipelago.

Data acquisition was semi-hourly and only diurnal observations from 06:00 to 21:00 UTC were considered. Analysed records cover a period of twenty two years, from January 1989 to December 2010. For La Palma, less observations than in the others airports were available because they were hourly until the end of March 2002 and semi-hourly from the beginning of April 2002 up to date.

In addition, to explore the fractal dimension behaviour and regional differences of rainfall, daily data from 28 rain gauges (automatic and manual) for an average period of $42 \mathrm{yr}$, from January 1969 to December 2010, have been analysed. Their locations are depicted in Figs. 1 and 2. These points have been selected on the basis of their geographical position, altitude and orientation, factors that contribute to explaining the observed rainfall regimes. Although time coverage varies between stations, the average recording period is considered suitable for the aims of the study.

Nomenclature used to denote each measurement station is described below. The islands are divided into two provinces: Las Palmas (P) and Sta. Cruz de Tenerife (T). The aerodromes of reference are named by the airport codes: G. Canaria A/P (GCLP), Lanzarote A/P (GCRR), Fuerteventura A/P (GCFV), Tenerife north A/P (GCXO), Tenerife south A/P (GCTS), La Palma A/P (GCLA) and El Hierro A/P (GCHI). The highest point is Izaña (T5) with an elevation $2371 \mathrm{~m}$. The main part of the rest of the stations considered in this work are sited in Gran Canaria (Fig. 2), the most suitable island for this study because of its relative central position in the archipelago and medium elevations.

\subsection{Synoptic conditions: numerical models}

Synoptic weather conditions favouring dust events over the islands have been detected by using analysis and reanalysis from numeric models over the three aerodromes of reference (Fuerteventura, Gran Canaria, and La Palma). This information covers a period of twenty one years, from January 1989 to December 2009. To detect and classify the more representative dust events, 36 episodes associated with visibility equal to, or lower than, $3 \mathrm{~km}$ due to haze or dust observations 


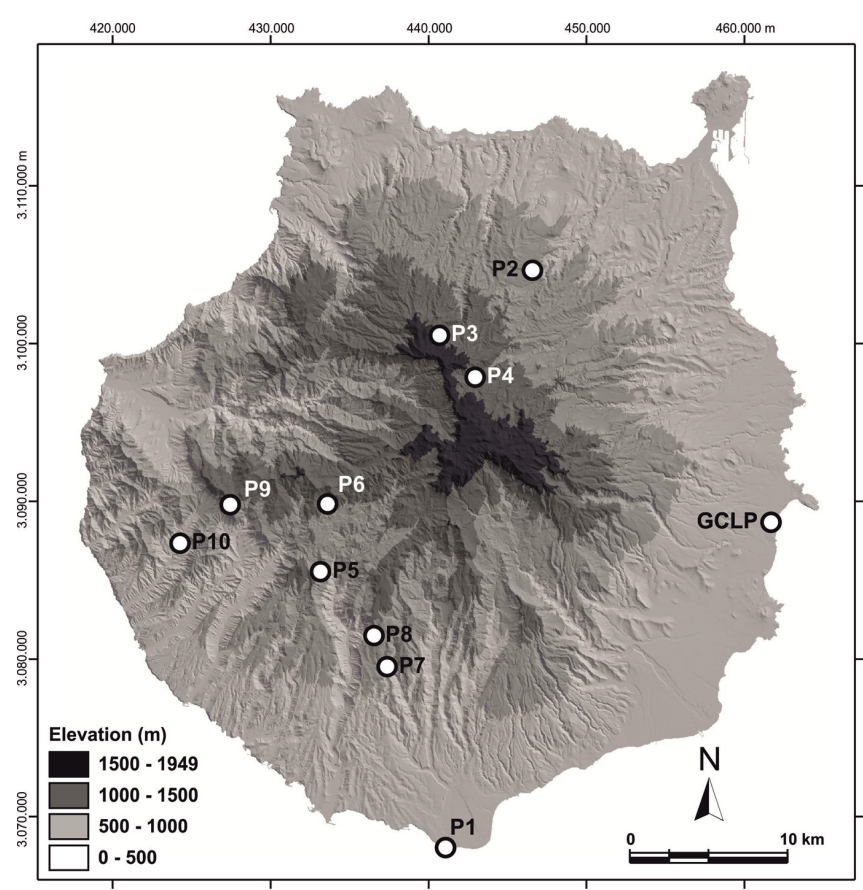

Fig. 2. Topographic map and geographic location of measurement stations in Gran Canaria.

have been considered. To such end, compositions of geopotential height, wind, temperature and humidity fields in different pressure levels were examined. The final synoptic classification was based essentially on the isobaric configurations favouring dust incursions in low levels. Mesoscale analysis was considered for some particular cases, playing an important role on the prevailing wind direction and contributing to drive dust over the areas of study.

Most synoptic charts used come from the ERA 40 reanalysis developed by the ECMWF (European Centre for Medium-Range Weather Forecasts) and included in the Meteorological Archival and Retrieval System (MARS). Additionally, these synoptic data were compared with reanalyses from the National Centre for Environmental Prediction (NCEP) and a counterpart of NOAA's Earth System Research Laboratory (ESRL), the National Center for Atmospheric Research (NCAR), which is supported by the National Science Foundation (NSF). The comparison between reanalyses from different numerical models showed a high consistency. Inspection of surface analysis charts revealed that the most frequent mechanism that brings dust over the islands corresponds to a system of high pressures in northern Algeria, the western Mediterranean, the Iberian Peninsula and even the northern Azores. This system is often accompanied by a depression in the vicinity of the Canaries, predominately situated in the south or southwest. Such a situation generates southeasterly winds favouring the dust invasion over the archipelago.

\subsection{Validation of dust events observations}

Despite being obtained by trained observers following a standardised procedure, as well as the special attention paid, including strict checking procedures due to its importance for air traffic, visual estimations of visibility entail some degree of subjectivity (Lerner et al., 2004). Two approaches have been applied to reduce uncertainty and improve confidence on visibility measurements derived from METARs. The first approach is based on the comparison of visibility data against in situ column optical depth data, gathered with a Cimel sunphotometer, and the other makes use of reanalysis information.

Aerosol optical depth (AOD) data recorded from 2005 to 2010 by an AERONET (AErosol RObotic NETwork) station installed in Sta. Cruz de Tenerife $\left(28.47^{\circ} \mathrm{N}, 16.24^{\circ} \mathrm{W}\right)$ at an altitude of $52 \mathrm{~m}$ has been used to validate and improve confidence on dust episodes information encoded in METARs.

AOD is a measurement of the dispersion and absorption of the visible light by the particles in a vertical column of the atmosphere. Hence, it provides information on the degree to which aerosols prevent the transmission of light and consequently represents an indicator of the amount of particulated matter in air. Among others authors, Ångström (1929) expressed its wavelength variation as $\mathrm{AOD}_{\lambda} \sim \lambda^{-\alpha}$, where the Angström exponent, $\alpha$, is a coefficient related to the aerosol size distribution and represents a measure of the relative abundance of fine to coarse-sized particles. The combined use of the $\mathrm{AOD}_{\lambda}$ and the Ångström exponent estimated for a given pair of wavelengths, $\alpha_{\lambda_{1}-\lambda_{2}}$, is a useful approach to distinguish aerosols of diverse origin or types (e.g. Holben et al., 2001).

Some parameters like $\mathrm{AOD}=\mathrm{AOD}_{675_{\mathrm{nm}}}$ and $\alpha=\alpha_{440-870_{\mathrm{nm}}}$ have been used by other authors (e.g. Basart et al., 2009) to characterise atmospheric aerosols in different AERONET sites around the Sahara (Holben, et al., 2001) and to establish some reference to distinguish desert mineral dust from other aerosol types. According to these authors, pure Saharan dust conditions are observed for $0.7<\mathrm{AOD}<5$, and $\alpha<0.3$. Additionally they conclude, by analysing data from Izaña AERONET station (with an elevation of $2371 \mathrm{~m}$ ), that Saharan dust can be represented by the pair AOD $>0.15$ and $\alpha<0.25$.

Owing to the difficulty in establishing reliable criteria to classify mineral dust in the area of the Canary Islands from AERONET measurements, only events satisfying the above conditions have been considered in the validation study.

Table 1 summarises the most representative dust occurrences recorded in METAR code, including the minor visibility and the dust event duration. The daily maximum value of AOD and the minimum of $\alpha$ for the record were initially taken into account according to the above-mentioned criterion. In general, selecting the maximum daily value of AOD and minimum of $\alpha$ for the record, most of the dust 
Table 1. Dust episodes encoded in METARs. Duration in hours and minor visibility in $\mathrm{km}$ for the Canaries. $\mathrm{AOD}_{675_{\mathrm{nm}}}>0.15$ and $\alpha_{440-870_{\text {nm }}}<0.25$ for Sta. Cruz de Tenerife (2005-2010).

\begin{tabular}{rrcllll}
\hline Episode & $\begin{array}{r}\text { Most dusty } \\
\text { day }\end{array}$ & Season & $\begin{array}{l}\text { Minor } \\
\text { visibility } \\
(\mathrm{km})\end{array}$ & $\begin{array}{l}\text { Duration } \\
(\mathrm{h})\end{array}$ & AOD & $\alpha$ \\
\hline 7-8 Feb 2006 & 8 Feb 2006 & W & 1 & 0.88 & 0.2262 & 0.1632 \\
7-11 Mar 2006 & 7 Mar 2006 & W & 5 & 4.33 & 0.6848 & 0.0775 \\
1 Apr 2006 & 1 Apr 2006 & Sp & 5 & 0.13 & 0.325 & 0.171 \\
3 Sep 2006 & 3 Sep 2006 & S & 1.5 & 0.68 & 0.736 & 0.1075 \\
6 Oct 2006 & 6 Oct 202006 & A & 7 & 0.02 & 0.904 & 0.0508 \\
9-12 Nov 2006 & 11 Nov 2006 & A & 1 & 2.50 & 0.3977 & 0.0302 \\
20-21 Nov 2006 & 20 Nov 2006 & A & 2 & 1 & 0.6382 & 0.1985 \\
11 Jan 2007 & 11 Jan 2007 & W & 3 & 0.12 & 0.3502 & 0.1991 \\
10 Mar 2007 & 10 Mar 2007 & W & 4 & 0.30 & 2.0293 & 0.1748 \\
20-21 Jan 2008 & 20 Jan 2008 & W & 1.8 & 1.47 & 0.4968 & 0.1869 \\
8 Feb 2008 & 8 Feb 2008 & W & 2.5 & 0.43 & 0.9298 & 0.1984 \\
3-4 Apr 2008 & 3 Apr 2008 & Sp & 2.5 & 1.35 & 0.6672 & 0.1765 \\
25-27 Apr 2008 & 26 Apr 2008 & Sp & 2.5 & 2.03 & 0.6063 & 0.2269 \\
27 Jun 2008 & 27 Jun 2008 & S & 5 & 0.17 & 0.5469 & 0.2096 \\
17-18 Jan 2010 & 18 Jan 2010 & W & 3 & 0.98 & 0.1682 & 0.1551 \\
7 Feb 2010 & 7 Feb 2010 & W & 4 & 0.77 & 1.0564 & 0.0357 \\
\hline
\end{tabular}

occurrences and the longest ones were related to a high AOD value and a low value of $\alpha$.

Figure 3 displays the temporal evolution of $\mathrm{AOD}_{675_{\mathrm{mm}}}$ at Sta. Cruz de Tenerife, the duration of the dust episodes in days and the visibility in $\mathrm{km}$ derived from data sets in METAR code in the Canaries from 2005 to 2010 (for visibility and duration only the episodes included in Table 1 are represented).

Results point out that at least during the longest dust intrusions observed in surface, a value of AOD characteristic of desert aerosol was also recorded. At a first glance, the analysis of data depicted in Fig. 3 indicates a low relationship between visibility and AOD data. Nevertheless, a proper interpretation of these results must take into account various aspects. Firstly, visibility observations represent horizontal integrations at surface level, whereas AERONET measurements are vertically integrated values at a given surface point. Additionally, the existence of a thermal inversion layer at a level between 1000 and $1500 \mathrm{~m}$ during the main part of the year divides the trade wind flow into two layers.

Dust intrusion events are commonly detected above the marine boundary layer (MBL) (Bergametti et al., 1989) mainly in the SAL (the Saharan air layer) (Karyampudi et al., 1999; Westphal et al., 1988) during early summer to early autumn, while desert dust emissions below this layer are commonly observed during winter and autumn (e.g. AlonsoPérez et al., 2011). Results achieved by examining atmospheric conditions during dust storm occurrences agree with those reported by other studies (e.g. Jankowiak and Tanré, 1992; Chiapello et al., 1995; Alonso-Pérez et al., 2007) which suggest that dust transportation over the NW African

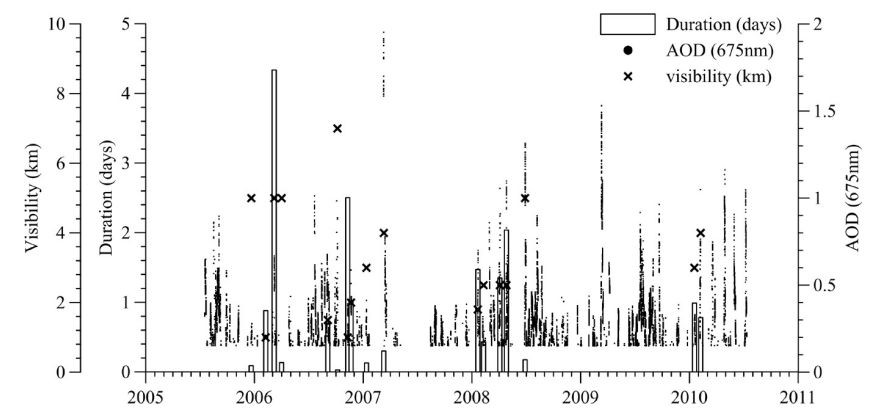

Fig. 3. Dust event duration in days (bars), surface visibility in $\mathrm{km}$ (circles) for Canaries, and AOD $657 \mathrm{~nm}>0.15$ for Sta. Cruz de Tenerife (dots) for the period 2005-2010.

coast takes place in wintertime, predominately from December to May.

In agreement with these results, dust episodes detected through METARs were also more frequent in winter, which supports the suitability of such observations for the intent of this study.

In summary, dust intrusions can occur at high or low levels. AERONET measurements detect both type of events, but METAR data include only low-level events. Consequently, dust events examined in the present study are only those detected in atmospheric lower layers, which are very important due to their influence on human activities.

The second approach to validate information on dust episodes encoded in METARs has been based on the use of information on synoptic atmospheric conditions, derived by reanalysis from numerical models. Following the experience 
gained from previous studies (Alonso-Pérez et al., 2011), results from this analysis reveal that, regarding the dust events coming from the low troposphere affecting the islands, the most frequent mechanism corresponds to a system of high pressures in general located in northern Africa. This system is often accompanied by a depression in the vicinity of the Canaries, predominately situated in the south or southwest and relatively close to the western African coast. Such a situation generates southeasterly winds favouring the dust invasion over the archipelago. It is interesting to remark that during winter the Azores High weakens and displaces from its normal position (Díaz et al., 2001), which favours the synoptic scenario mentioned above.

Results from the analysis of prevailing winds extracted from METARs when desert dust intrusions affect the islands increase the robustness of visibility surface observations used in this work. Thus, when the presence of such phenomena implies visibilities equal to, or lower than, $3.5 \mathrm{~km}$, a southerly or southeasterly wind pattern prevails and reveals dust emissions stemming from the Sahara.

\section{Methodology}

A time series of a process shows scaling properties if it has the same statistical properties within a considerable range of scales. Exploring the existence of power law frequency statistical behaviour and fractal properties in time series of natural system has shown to be a successful approach to characterise their complexity (Mandelbrot, 1983; Schertzer, 2012). This section introduces the methods used in the present work to examine the scaling properties of rainfall and Saharan dust events in the studied area.

\subsection{Power law frequency statistics}

Scaling invariance is present in a given process if the probability or frequency-size distributions of events (intensity or duration) obeys a power law (PL hereafter) relationship of the type $f(x)=C x^{-\beta}$, where $C$ is a constant, the value of $f(x)$ is proportional to some power of the input $x$, and $\beta$ is the scaling exponent (e.g. White et al., 2008). In a log-log representation, this power law distribution becomes a straight line and the scale exponent, $\beta$, is given by its slope. This behaviour occurs for values of the explanatory variable, $x$, higher than a given threshold, $x_{0}$, that is, in the tail of the distribution.

Phenomena which follow PL distributions are widespread in natural and social disciplines (e.g. Malamud and Turcotte, 2006). An important implication is that a PL is heavy-tailed, which indicates that extreme events occur at a higher frequency more than in other distributions such as the normal or exponential (e.g. Stumpf and Potter, 2012). Apart from this, the detection of a PL pattern in empirical data or in the time interval between them may indicate the presence of either long-range correlations or unusual underlying mechanisms like feedback loops, random network, self-organisation or phase transitions (West et al., 1997; Barabasi and Albert, 1999; Newman et al., 2006). This hypothesis also suggests possible presence of long-range correlations.

One important limitation of this tool is the occurrence of the power law behaviour at the tail of the distribution where it is desirable to have the best accuracy (Stumpf and Potter, 2012). The tails of the empirical distributions present the largest fluctuation due to a lower number of observations. As a result of this, the uncertainty of the estimation of the exponent increases. Nevertheless, in this work, our aim is merely to provide a qualitative analysis on the existence of a power law behaviour in the examined phenomena, but not to obtain the exact power law pattern exhibited by the processes. On the other hand, the scaling laws do not always provide the best fit. Alternative distributions to characterise these environmental phenomena are the lognormal (Mitzenmacher, 2003), the stretched exponential (Laherrère and Sornette, 1998) and other truncated PLs (Burroughs and Tebbens, 2001; Tsallis, 2009). In spite of these difficulties, an advantage of the application of PL tools for diagnostic, characterisation and even prediction purposes is its simplicity. Moreover, in recent years, improved statistical tests have provided strong evidence of scaling laws over a substantial, although limited, range of scales (Clauset et al., 2009; Virkar and Clauset, 2012).

\subsection{Fractal dimension}

Non-equilibrium phenomena following power laws verify general scaling relations and are, by definition, self-similar (Schroeder, 1991; Boettcher and Paczuski, 1996). Selfsimilarity is a key concept in the scaling properties exploration because it means that small sections of a time series cannot be distinguished from the whole signal after being properly scaled. That is, self-similar time series have a fractal structure. Thus, knowledge of its fractal dimension provides a way to relate information at different scales (e.g. Malamud and Turcotte, 2006).

Many algorithms to estimate the fractal dimension have been proposed, each one with its advantages and drawbacks. The box-counting method is the oldest and more commonly used because it is intuitive and easy to apply (Lovejoy et al., 1987; Olsson et al., 1992, 1993). This technique has been successfully used on different natural processes like earthquakes (Chen et al., 2003), desert storms (Mayer, 1992), floods (Mazzarella and Rapetti, 2004), volcanology (Dubois and Cheminee, 1991), El Niño events (Mazzarella and Giuliacci, 2009), rainfall (Olsson et al., 1992,1993; Izzo et al., 2004; de Lima and de Lima, 2009) and eolian dust deposits on desert alluvial terraces (Pelletier et al., 2007).

The method employed in this study to estimate the fractal dimension of dust and rain events is known as the Cantor dust method considered by other authors as a proper framework 
for non linear analysis like the fractal behaviour of rainfall occurrence (Mazzarella and Diodato, 2002). It is in fact a box-counting algorithm in which the space of observation represents the total length of the time series and the boxes correspond to the time intervals. The intervals or clusters of dust or rain events are taken as natural point processes (e.g. Mandelbrot, 1983; Turcotte, 1997; Takayasu, 1990). Thus, when applied to a time series, this method is based on dividing the space of observation, the time interval, $T$, into $n$ non-overlapping segments of characteristic size, $s$, such that $s=T / n$ for $n=2,3,4, \ldots$, and computing the number $N(s)$ of intervals of length $s$ occupied by events. If the distribution of events has a fractal structure, then the relationship $N(s)=C s^{D}$ holds. The fractal or box-counting dimension $D_{\mathrm{f}}$ is estimated from the slope $D$ of the regression line of $\log (N(s))$ on $\log (s)$. This parameter, $D_{\mathrm{f}}=|D|$, describes the strength of the rainfall or dust events gathered and can be used as a measure of the nature of the phenomenon, since it quantifies the scale-invariant clustering of the time series (Mazarella, 1998; Mazarella and Diodato, 2002). Clustering increases when $D$ approaches 0 . So, the smaller fractal dimensions correspond to clusters formed by events that occur sparsely (Izzo et al., 2004). If $D$ is close to 1 , the events are randomly spaced in time. That is, they correspond to a more dense or uniform distribution and not to time clustering.

To sum up, the box-counting method uses boxes to cover an object to find the fractal dimension (Olsson et al., 1992, 1993; de Lima and de Lima, 2009). The signal is partitioned into boxes of various sizes and the amount of non-empty squares is counted. A log-log plot of the number of boxes versus the size of the boxes is done. Signal binarisation, i.e. whether a box is occupied or not, implies a limitation of the method.

\section{Results and discussion}

\subsection{Dust outbreak power-law}

Time series of minimum visibility registered during dust event occurrences over the Canaries, extracted from hourly records from the reference aerodromes (METARs), is shown in Fig. 4a, while the corresponding duration of each event is represented in Fig. 4b. It can be observed that there is no significant correlation between the intensity (reduced visibilities) of the dust intrusions and their durations. That is, prolonged intrusions do not commonly imply higher intensities and vice versa. Scatter plots (not shown) appear randomly when intensity versus duration is represented. Determination coefficients of linear regression are $R^{2}=0.09$ for Gran Canaria, $R^{2}=0.18$ for La Palma and $R^{2}=0.16$ for Fuerteventura. These time series also present a wide interannual variability, which becomes clearer in the bar chart depicted in Fig. 5, in which the height of each bar indicates the number of events recorded during that year.
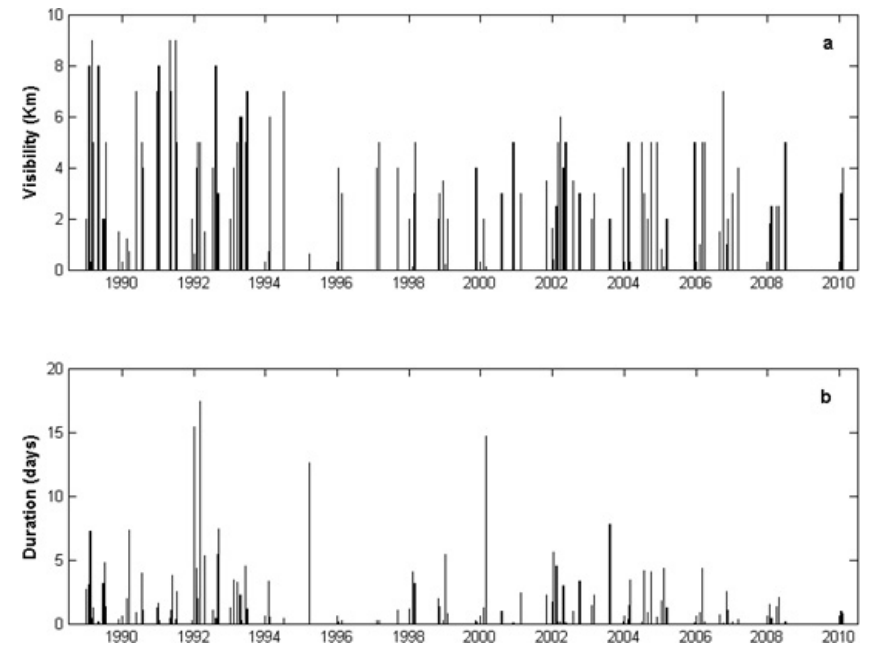

Fig. 4. Visibility (km) (a) and duration (days) (b) of dust events (HZ, DU, DRDU or DS) over the Canaries for the period 19892010 (METARs).

The average number of events per year during the $22 \mathrm{yr}$ period (1989-2010) analysed is close to 5 events per year, but clear dispersion around this value is observed with time. At a first glance, values of visibility reduction and duration of events represented in Fig. 4 reveal that, even when variability is notable, dust intrusions have a greater chance of occurring during winter months. This fact is clarified by representing the total number of events recorded during each month for the whole period (see Fig. 5 inset). During the study period, the number of dust intrusions that occurred from April to December is very similar. However, this uniformity disappears during the wintertime, where the frequency of occurrence experiences a noticeable increase peaking in February.

Results from the seasonal analysis of dust events affecting low altitudes in the archipelago agree with those derived from the examination of synoptic conditions driving dust intrusions at low atmospheric levels and with previous studies (e.g. Jankowiak and Tanré, 1992; Viana et al., 2002).

Figure 6 provides the distributions of dust event duration over the same locations. The frequency of dust occurrences is represented versus the number of consecutive dusty days. The histogram evidently shows that dust events of a short duration are more probable, whereas long events are rare, which may correspond to extreme events. The goodness of fit to a straight line obtained in the $\log$-log representation shown in the inset figure, with $R^{2}=0.96$ and root mean square error $(\mathrm{RMSE})=0.29$, reveals the presence of a PL relationship between the frequency of occurrence of dust events and their duration, in which the slope or scale exponent is $\beta=-1.49 \pm 0.28$.

\subsection{Power law of dry periods}

The duration of intervals between rainy events in Gran Canaria $\mathrm{A} / \mathrm{P}$ has been analysed by using the long data set 


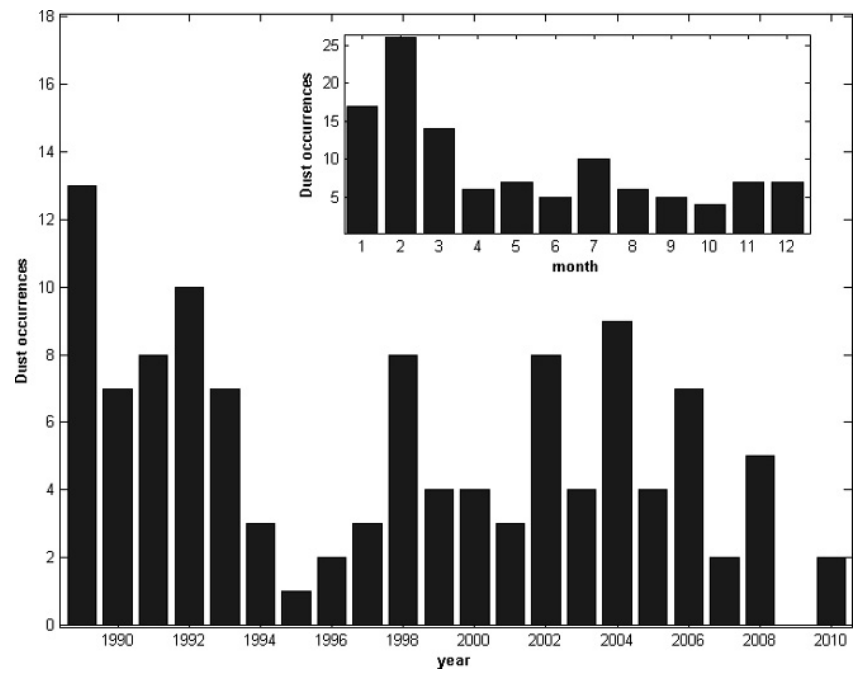

Fig. 5. Interannual and seasonal (inset figure) variability of dust occurrences over the Canaries during the period 1989-2010 (METARs).

derived from METARs, to gain insight on the rainfall time distribution over the archipelago. This station has been selected because of the available long data set and its geographical location. It is important to note that METARs only take into account the occurrence or non-occurrence of rain events but not their intensity. This implies that a light rain is considered as rainfall occurrence in the same way as a heavy one. Hence, dry periods could be even longer than those detected in this study.

The number of dry periods as a function of the durations is represented in Fig. 7. It can be observed that the number of dry events decreases sharply for low and moderate durations, but a small number of notably large events are present in the upper tail, with dry periods between rain events reaching durations of about 5 months. This fact evidences that the data follow a heavy tail distribution and suggests that they may exhibit a power law behaviour. The log-log plot of the frequency of dry spells versus duration shown in the inset of Fig. 7 reveals the existence of a PL with exponent $\beta=-1.75 \pm 0.25\left(R^{2}=0.90\right.$ and RMSE $\left.=0.42\right)$. As commented previously, it is remarkable that for very large durations data are scarce and sparse, and therefore this may influence the computed values of the exponent.

These results agree with those reported in other studies (e.g. Mazzarella, 1999; Izzo et al., 2004). In general, the presence of long tail distributions is an indicator of the absence of some statistics like the mean or the variance, in particular for values of $|\beta|<2$, as those found in this work. When analysing dust and dry spell frequencies presented in this section, such statistics could be interpreted as infinite. This kind of distribution reveals the possibility of natural hazards (Cello and Malamud, 2006) and also suggests the existence of scale-invariant properties underlying critical phenomena

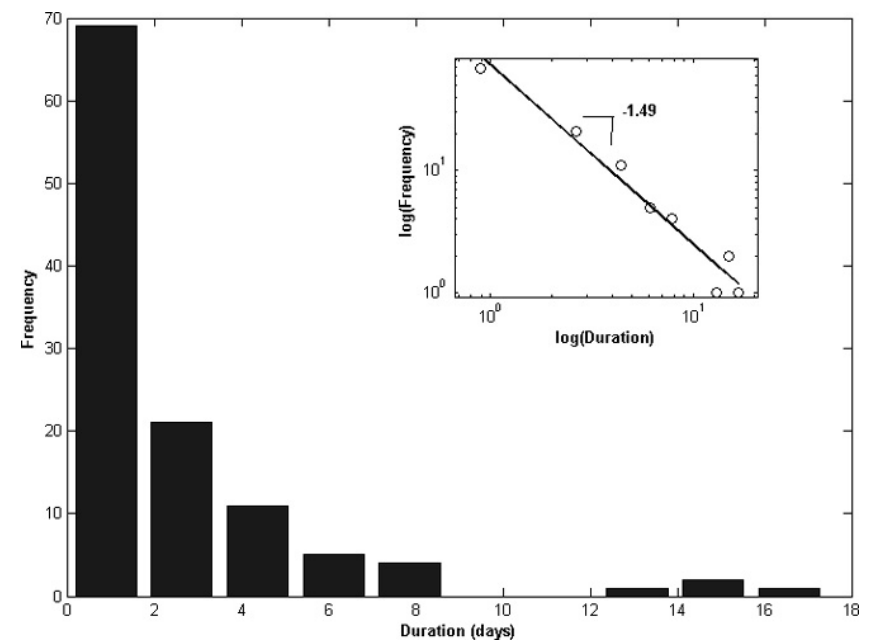

Fig. 6. Histogram of dust events duration over the Canaries for the period 1989-2010 from METARs and log-log representation with fitted straight line (inset figure).

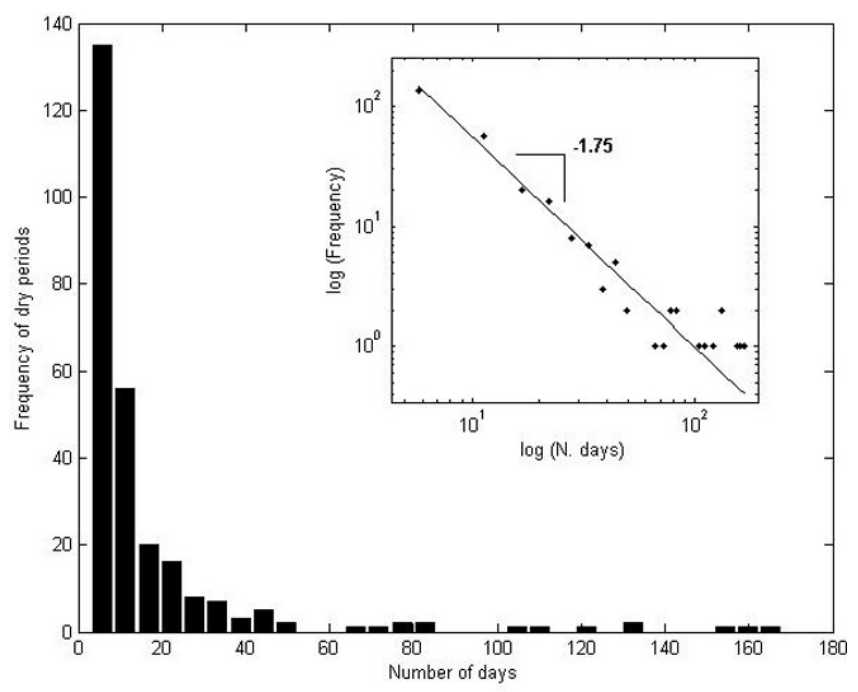

Fig. 7. Histogram of time intervals (in days) between rain events for Gran Canaria airport, METARs (1989-2010), and log-log representation with fitted straight line (inset figure).

(Sornette, 2004). Occurrences of dust and rain events following power laws might point out the existence of selforganised criticality, such as manifested in the high diversity of the climatic, topographic, or botanic features found throughout the archipelago.

\subsection{Fractal characteristics}

Fractal behaviour of the dust occurrence regime has been examined by using time series extracted from METARs. To this end, semi-hourly data from reference aerodromes have been considered. The same approach has been followed to explore fractal characteristics of rainfall events. The fractal 


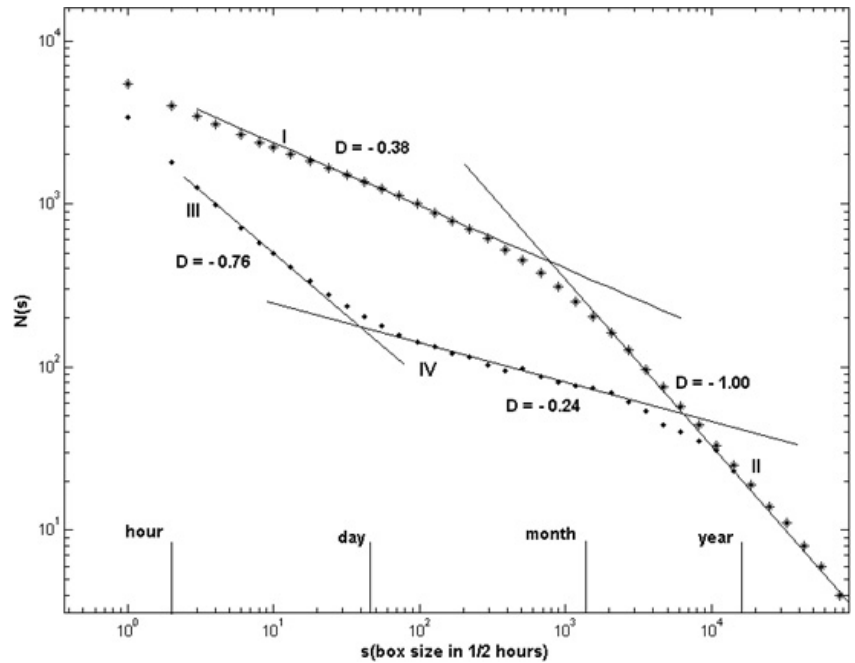

Fig. 8. Box-counting $\log -\log$ plots and slopes, $D$, for the rainfall (asterisks) and dust event (dots) data series at Gran Canaria airport, and METARs for the period 1989-2010.

dimension of a set of long rainfall time series has been analysed to gain a better understanding of the spatial distribution of rainfall occurrences over the archipelago. Data were recorded from automatic and manual weather stations located in the points depicted in Figs. 1 and 2. For this purpose, the Cantor dust method has been used. Results are presented in the following subsections.

\subsubsection{Dust and rainfall occurrences in reference aerodromes extracted from METARs}

Results of the fractal analysis for dust and rainfall events in Gran Canaria airport (GCLP) are shown in the Fig. 8, while general results, including the other two reference aerodromes (GCFV and CGLA), are summarised in Table 2.

The number $N(s)$ of intervals of length $s$ containing at least one dust or rain event as a function of the interval length are plotted in a bi-logarithmic graph. Straight-line segments fitted by regression are constructed over different scale intervals. The smallest time interval chosen was approximately half an hour and gradually increased by a factor of 2. The fractal dimension, derived from the slope, $D_{f}=|D|$, ranges from 0 to 1 .

Figure 8 reveals the existence of segments (timescales) with different behaviour separated by crossovers or cutoffs. These break points can be interpreted as characteristic time periods when changes in the temporal structure of the phenomena distribution take place (Olsson et al., 1993) or as a combination between scale-invariant clustering and random occurrence of events (Smalley et al., 1987). Between two segments or scaling regions there are transitions where the environmental properties are probably changing rapidly. Segments at each side of these transitional zones have been indicated with Roman numbers from I to IV. The regres-
Table 2. Results of the box-counting analysis (scaling range, SR; fractal dimension, $D_{\mathrm{f}}$; and associated RMSE) of the dust and rain event data series from hourly surface data in reference aerodromes for the period 1989-2010. (Scaling range is given in hours, h, days, $\mathrm{d}$, and months, $\mathrm{m}$ ).

\begin{tabular}{cccccccc}
\hline Station & \multicolumn{3}{c}{ Dust } & & \multicolumn{3}{c}{ Rain } \\
\cline { 2 - 3 } \cline { 6 - 8 } & SR & $D_{\mathrm{f}}$ & RMSE & & SR & $D_{\mathrm{f}}$ & RMSE \\
\hline \multirow{2}{*}{ GCLP } & $1-8 \mathrm{~h}$ & 0.76 & \pm 0.017 & & $1 \mathrm{~h}-6 \mathrm{~d}$ & 0.38 & \pm 0.027 \\
& $2 \mathrm{~d}-2 \mathrm{~m}$ & 0.24 & \pm 0.017 & & & & \\
& & & & & & \\
GCFV & $1-8 \mathrm{~h}$ & 0.76 & \pm 0.021 & & $1 \mathrm{~h}-6 \mathrm{~d}$ & 0.27 & \pm 0.027 \\
& $2 \mathrm{~d}-2 \mathrm{~m}$ & 0.30 & \pm 0.023 & & & \\
GCLA & $1-8 \mathrm{~h}$ & 0.79 & \pm 0.032 & & $1 \mathrm{~h}-6 \mathrm{~d}$ & 0.41 & \pm 0.036 \\
& $2 \mathrm{~d}-2 \mathrm{~m}$ & 0.29 & \pm 0.037 & & & \\
\hline
\end{tabular}

sion line shows for timescales ranging from 1 to nearly $8 \mathrm{~h}$ a $D=-0.76$ (segment III). This slope, steeper than that associated with segments I and IV, unveils a dense and uniform organisation of dust events in the time domain. This corresponds to a distribution of dust cells poorly clustered for a period shorter than a day.

Following a conviction common to many existing studies (e.g. Mazzarella and Giuliacci, 2009), a regular time distribution of events produces a rise in $D_{\mathrm{f}}$ up to the limiting value $D_{\mathrm{f}}=1$. The break, close to one day, may indicate periods of good visibility in terms of mineral outbreaks over the islands between dust events. A curved segment appears close to the time interval between 8 and $10 \mathrm{~h}$ and approximately two days representing a transition phase. Other scaling region can be observed at timescales ranging from two days to approximately two months (segment IV) for which the fractal dimension is $D_{\mathrm{f}}=0.24$. The slope of this intermediate segment, comparatively small, evidences that dust events are organised in clusters dispersed over this timescale. Another transition phase is found between 2 months and roughly seven months, when the saturation is reached for the dust events, represented by the straight line II, with a slope close to 1 . This implies that, on average, at least one dust event occurs over this Atlantic area for time periods exceeding seven months.

Rainfall events observed over the islands exhibit a different fractal behaviour to that observed for desert aerosol outbreak occurrences. In this case, the first segment (I) corresponds to a box-size interval from $1 \mathrm{~h}$ to 6 days, and is characterised by a $D_{\mathrm{f}}=0.38$, revealing a similar scaling pattern within this time range. This $D_{\mathrm{f}}$ value indicates a scaling regime and an irregular distribution of the rainfall at this timescale. In this time interval, rain events can be closely gathered while long dry episodes are observed between them. Consequently, on average, precipitation is not evenly spread throughout this time interval. For time increments above 6 days the slope of the curve approaches -1 (segment II). Rainfall events occurring for time increments exceeding two 
months represent the saturation of the process $\left(D_{\mathrm{f}}=1\right)$. In a statistical sense, this means that rainfall events have a similar frequency of occurrence for time increments greater than two months. Results obtained by applying the Cantor dust method suggest that each segment is related to a different underlying process that explains the occurrence of the dust or rainfall events according to each range of time.

Regarding analogous observations taken in other aerodromes of reference, La Palma airport was chosen to represent the wettest islands, building upon the influence of the Atlantic low-pressure systems that affect the western part of the archipelago mainly during the winter season. On the other hand, an eastern and drier one, Fuerteventura airport, was selected due to its proximity to the western African coast with the Sahara as the main aerosol source. Table 2 summarises the box-counting fractal dimensions $\left(D_{\mathrm{f}}\right)$ from the analysis of dust and rain data series, as well as the RMSE. Values of $R^{2}$ for dust analysis range from 0.97 in La Palma to 0.99 in the rest of the airports. The coefficient of determination for rainfall in Fuerteventura and La Palma is 0.98, and 0.99 in Gran Canaria.

The $D_{\mathrm{f}}$ values obtained from the analysis of the dust events are very close. This is because the timing of dust events is the same for all the islands and consequently the resulting clustering pattern is very similar.

Regarding precipitation, at a time increase of about one week, the steepest gradient and the highest $D_{\mathrm{f}}$ value $(0.41)$ correspond to La Palma, the rainiest island.

In contrast, the lowest $D_{\mathrm{f}}$ value $(0.27)$ is found in Fuerteventura, which is flat, evidently showing a strong clustering behaviour, since rain occurrences are scarce and irregularly distributed in time. In this case the dry periods are longer than the episodes of rain. For periods of time, between one day and one week, La Palma and Gran Canaria present higher $D_{\mathrm{f}}$ for rainfall than for dust events; thus rain occurrences are more uniformly spread over this period of time and shorter dry episodes are observed. La Palma offers a relatively high fractal dimension for the rainfall analysis, $D_{\mathrm{f}}$, value (0.41) and thus is more affected by rain due to its geographical location and influence of Atlantic lows. Nevertheless, at this scale time, the dust event time pattern in Fuerteventura shows a value of $D_{\mathrm{f}}$ slightly higher than for rain occurrences, such as corresponds to a more arid climate. Comparing both phenomena, in general, for a timescale of about one day, dust or haze events (HZ) are more closely distributed than rainfall ones. In other words, dust is more persistent than rainfall throughout the day. This implies that they are affected by meteorological processes acting at different timescales.

\subsubsection{Rainfall over the archipelago}

Rainfall occurrences affecting the islands are generally associated with typical synoptic unstable situations such as cold depressions (located at N, NE and E or at SW, W and NW of
Table 3. Fractal dimensions $\left(D_{\mathrm{f}}\right)$ of the rainfall data series and percentage of annual number of rainy days at the Canaries. Daily data from automated and manual stations. Average period of measurements: 1969-2010.

\begin{tabular}{cccc}
\hline $\begin{array}{c}\text { Fractal } \\
\text { dimension }\end{array}$ & $\begin{array}{c}\text { Elevation } \\
\text { range }(\mathrm{m})\end{array}$ & $\begin{array}{c}\text { Islands } \\
\text { sector }\end{array}$ & $\begin{array}{c}\% \text { annual } \\
\text { rainy days }\end{array}$ \\
\hline $0.20-035$ & $15-806$ & $\mathrm{~S} / \mathrm{SE}$ & $17-31$ \\
$0.36-0.40$ & $106-950$ & $\mathrm{~W} / \mathrm{NW}$ & $26-47$ \\
$0.41-0.45$ & $1040-2371$ & $\mathrm{C}$ & $34-42$ \\
$>0.45$ & $33-1400$ & $\mathrm{~N} / \mathrm{NE}$ & $46-94$ \\
\hline
\end{tabular}

the islands) and mobile troughs with or without fronts (irregular situations). These disturbances are usually accompanied by an intensified advection which occurs south of the low cores, breaking the inversion layer and providing abundant wet air or the effect of frontal tails associated with North Atlantic low-pressure systems.

Table 3 examines the fractal dimension estimates based on the altitude, location of the stations and the percentage of the rainy days. These were assessed throughout the year excluding the months from June to August. Figure 9 gives a summary of the main results of the rainfall analysis and displays the $D_{\mathrm{f}}$ estimates by amount (circles with different sizes and colour), which are drawn on the Canary archipelago map according to their locations. In particular, the results demonstrate the variability of the rainfall fractal dimension with latitude, altitude and longitude.

As results, the higher $D_{\mathrm{f}}$ values were estimated in the northern (GCXO, P3) and central (P4) sectors of the islands ( 0.47 and 0.59 , respectively) compared to those located at the southern and eastern sides (from 0.20 to 0.35 ). This explains why the majority of rainfall events are observed at northern sites (windward sides of the islands).

A further factor that clearly influences precipitation over the islands is the relief. This factor also modifies the fractal behaviour of the rain trend. The higher stations (with elevations between 1000 and $2370 \mathrm{~m}$ ) located at the central area of the islands (P6 and T5) also presented values of $D_{\mathrm{f}}$ near 0.4 . In most cases these values are higher than those estimated at flatter locations, but with some exceptions. For instance, T7 and T11, with medium elevations between 840 and $1200 \mathrm{~m}$, exhibit a relatively high $D_{\mathrm{f}}$ between 0.43 and 0.45 . These stations, in spite of having a leeward position, are very affected by low-pressure systems. In contrast, T8 at a lower altitude shows a higher $D_{\mathrm{f}}(0.47)$ because of its northern location. This station is more affected by the frontal tails linked to North Atlantic lows.

There is an evident gradual increase of $D_{\mathrm{f}}$ in the archipelago from east to west. Another result is that among the eastern islands there are examples of southern or eastern flatter sites, like P1 or GCFV, which are strongly influenced by the Sahara, showing low $D_{\mathrm{f}}$ values between 0.31 and 0.33 . On the other hand, western stations on the western 


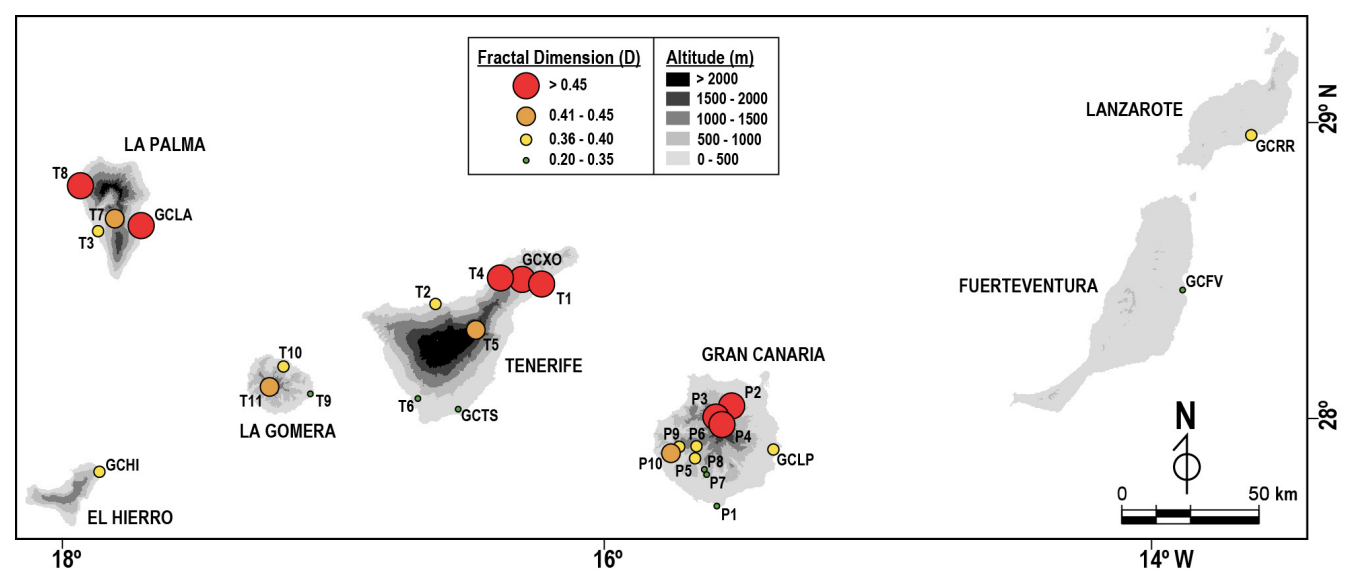

Fig. 9. Spatial variability of rainfall fractal dimension over the Canaries.

islands (T7, T11 and T8) show a higher $D_{\mathrm{f}}$ than those in eastern or central islands, such as P5, P9 or P6. It should be noted that a low $D_{\mathrm{f}}$ does not necessarily imply fewer annual rainfall events, but a higher clustered pattern and consequently longer dry periods. Nevertheless, results show as a general pattern that stations with a large number of annual rainy days present a relatively high $D_{\mathrm{f}}$ value (Table 3 ).

Due to its central location in the archipelago, topographic structure, and the influence of different synoptic situations, the precipitation regime properties of Gran Canaria have been analysed in more detail. The special relief of this island allows clear differentiation between windward and leeward sides determined by the thermal inversion layer located between approximately 900 and $1500 \mathrm{~m}$. Fractal dimension for northern Gran Canaria locations (P2, P3 and P4) ranges from $D_{\mathrm{f}}=0.48$ to $D_{\mathrm{f}}=0.56$. In general, points located at the thermal inversion layer level (P4) show larger $D_{\mathrm{f}}$ values (0.56) than those situated below (P2) or above (P3) this level. However, fractal dimension for southern locations (P1, P7, P8 and $\mathrm{P} 5)$ ranges from 0.31 to 0.36 . The flatter point (P1) presents the lower value among all the studied stations. This lower $D_{\mathrm{f}}$ value reveals desert-like precipitation behaviour. Eastern stations (GCLP) also present lower $D_{\mathrm{f}}$ values than the northern ones. An exception is P10, a station located in the westsouthwest of Gran Canaria with a relatively high $D_{\mathrm{f}}$. This is due to the major influence of systems of low pressures affecting the SW sectors of the islands, which provide abundant wet air and rainfall.

In summary, results obtained from this analysis attest to a clear change of the fractal behaviour between islands as a function of the geographical features (elevation and geographical orientation). Even on a given island, there is a noticeable change in the clustering regime as a result of the orientation and elevation of the stations where the phenomenon is measured.

It is worth mentioning that analyses carried out in Madeira (de Lima and de Lima, 2009) reveal a similar general pattern to that found in the present study, with larger $D_{\mathrm{f}}$ values at northern or central locations and lower values in southern sectors. Absolute values of the fractal dimension for a given geographical sector are lower in the Canaries.

In Madeira $D_{\mathrm{f}}$ values are approximately 0.71 at northern locations and close to 0.75 in central highlands and to $0.53-$ 0.56 for southern sectors (de Lima and de Lima, 2009). In the Canaries $D_{\mathrm{f}}$ values are, in general, lower and widely scattered and range between 0.29 and 0.59 . Only some northern stations like GCXO, or those of a higher altitude than $1100 \mathrm{~m}$ like P3 and P4, show similar $D_{\mathrm{f}}$ to the stations of Madeira, reaching a $D_{\mathrm{f}}$ between 0.54 and 0.59 . Differences in fractal properties at both archipelagos can be explained in terms of geographic and topographic features. Naturally, the Canaries are more exposed to influence from the African continent and less affected by the Atlantic lows than the Portuguese islands, which present a higher annual rainfall.

Studies developed in regions with a pluviometric regime defined by longer periods of rain, such as the city of Lund in Sweden (Olsson et al., 1993) or in Madeira (de Lima and de Lima, 2009), reveal that the saturation of the process occurs for roughly one week, showing a rain pattern evenly distributed over the year with small changes between seasons (Olsson et al., 1993). The saturation for periods longer than a week implies inherent deficiencies of applying the box-counting method to study rainfall events, mainly when time series of a relatively small size are used (de Lima and de Lima, 2009). Hence, for example, for time intervals exceeding roughly two months, an isolated rain event will be found in an interval filling a box. This may incorrectly indicate a pattern which does not fully describe the nature of the phenomenon. For this reason, analysis of the dry periods between the aforementioned rain events is developed in this work to provide a better understanding of the scale analysis of rainfall events over this region. 


\section{Conclusions}

As was the motivation for this work, we think that the temporal scaling properties as well as the spatial variability of rainfall events and desert aerosol outbreaks in the Canary Islands have become better understood. The desert dust intrusions over the Canary islands have been characterised through METARS, in terms of its relationship with visibility, and the suitability of these kinds of observations has been proved to this end. In agreement with previous studies, the initial step of this work detects a seasonal pattern of dust incursions over the archipelago, with the maximum in the winter and the minimum at the beginning and end of the summer, as well as during the autumn.

Analysis of dust and rainfall events over the islands exhibits distributions in time that obey power laws. This implies the existence of frequency distributions with long tails, revealing the possibility of natural hazards. In particular, long dry periods between rain occurrences are observed over the study area. Furthermore, the presence of PL distributions also suggests the existence of scale-invariant properties underlying critical phenomena.

Scaling characteristics from the analysed records are evidence of fractal behaviour with different patterns of time clustering in the examined parameters, which are directly linked with scale-invariant processes.

For dustiness, two different patterns are distinguished: a moderate gathering one scaling from 1 to $8 \mathrm{~h}$, and another ranging from two days to two months with high clustering which responds to a large-range transport aerosol model. In contrast, the duration of the rainfall events rarely exceeds one week. These results sheds light upon the pluviometric regimen over the islands, characterised by long periods with widespread and light or moderate rainfall occurrences but occasional short episodes of torrential and localised ones. It highlights that rainfall over the Canary Islands has statistically the same irregular behaviour in terms of temporal distribution independent from the temporal scale of measurement.

Comparison of rainfall fractal characteristics from automated and manual stations reveals that geographical features of the selected stations like the location, orientation and elevation are crucial factors. Sites located in the northern and higher sectors of the islands have, in general, a larger $D_{\mathrm{f}}$ than those in southern, eastern or flatter ones, which respond to a more arid properties. Locations affected by the cloud layer show larger $D_{\mathrm{f}}$ values than those situated below and above it. Furthermore, the fractal dimension increases in the archipelago from east to west.

Acknowledgements. We gratefully acknowledge the input and suggestions of our colleagues at ULPGC (University of Las Palmas of Gran Canaria) for the preparation of this work, especially M. C. Cabrera-Santana and A. Rodríguez-González (GEOVOL Group Research Department of Physics) for providing topographic maps. We are also grateful to E. Howell and N. Avery (University of Southampton) for reading a preliminary version of the paper. Finally, we would like thank A. Mazzarella and another anonymous reviewer for their helpful comments.

This work was partially supported by AEMET (the National Meteorological Service of Spain), mainly with questions related to data inquiries.

Edited by: J. M. Redondo

Reviewed by: A. Mazzarella and one anonymous referee

\section{References}

Alonso-Pérez, S., Cuevas, E., Querol, X., Viana, M., and Guerra, J. C.: Impact of the Saharan dust outbreaks on the ambient levels of total suspended particle (TSP) in the Marine Boundary Layer (MBL) of the Subtropical Eastern North Atlantic Ocean, Atmos. Environ., 41/40, 9468-9480, doi:10.1016/j.atmosenv.2007.08.049, 2007.

Alonso-Pérez, S., Cuevas, E., Pérez, C., Querol, X., Baldasano, J. M., Draxler, R., and Bustos, J. J.: Trend changes of African air mass intrusions in the marine boundary layer over the subtropical eastern North Atlantic region in winter, Tellus B, 63, 255-265, doi:10.1111/j.1600-0889.2010.00524.x, 2011.

Ångström, A.: On the Atmospheric Transmission of Sun Radiation and on Dust in the Air, Geogr. Ann., 11, 156-166, 1929.

Arteaga, M. A., Delgado, J. D., Otto, R., Fernández-Palacios, J. M., and Arévalo, J. R.: How do alien plants distribute along roads on oceanic islands? A case study in Tenerife, Canary Islands, Biol. Invasions, 11, 1071-1086, 2009.

Baddock, M. C., Strong, C., Murray, P., and McTainsh, G.: Aeolian dust as a transport hazard, Atmos. Environ., 17, 7-14, 2013.

Barabási, A. L. and Albert, R.: Emergence of scaling in random networks, Science, 286, 509-512, 1999.

Basart, S., Pérez, C., Cuevas, E., Baldasano, J. M., and Gobbi, G. P.: Aerosol characterization in Northern Africa, Northeastern Atlantic, Mediterranean Basin and Middle East from direct-sun AERONET observations, Atmos. Chem. Phys., 9, 8265-8282, doi:10.5194/acp-9-8265-2009, 2009.

Bäumer, D., Vogel, B., Versick, S., Rinke, R., Möhler, O., and Schnaiter, M.: Relationship of visibility, aerosol optical thickness and aerosol size distribution in an ageing air mass over SouthWest Germany, Atmos. Environ., 42, 989-998, 2008.

Ben Mohamed, A., Frangi, J. P., Fontan, J., and Druilhet, A.: Spatial and temporal variations of atmospheric turbidity and related parameters in Niger, J. Appl. Meteorol., 31, 1286-129, 1992.

Bergametti, G., Gomes, L., Coudé-Gaussen, G. , Rognon, P., and Le Coustumer, M.-N.: African dust observed over Canary Islands: Source-regions identification and transport pattern for some summer situations, J. Geophys. Res., 94, 14855-14864, doi:10.1029/JD094iD12p14855, 1989.

Boettcher, S. and Paczuski, M.: Ultrametricity and memory in a solvable model of self-organized criticality, Phys. Rev. E, 54, 1082-1095, 1996.

Boffetta, G., Carbone, V., Giuliani, P., Veltri, P., and Vulpiani, A.: Power laws in solar flares: Self-organized criticality or turbulence?, Phys. Rev. Lett., 83, 4662-4665, http://dx.doi.org/10. 1103/PhysRevLett.83.4662,1999.

Boreson, J., Diller, A. M., and Peccia, J.: Correlating bioaerosol load with PM2.5 and PM10cf concentrations: a comparison 
between natural desert and urban-fringe aerosols, Atmos. Environ., 38, 6029-6041, doi:10.1016/j.atmosenv.2004.06.040, 2004.

Burroughs, S. M. and Tebbens, S. F.: Upper-Truncated Power Laws in Natural Systems, Pure Appl. Geophys., 158, 741-757, 2001.

Cello, G. and Malamud, B. D.: Fractal analysis for natural hazards, Geological Society Publishing House, London, 2006.

Chen, Y.-C., Sung, Q.-C., Yu, T. T., and Sun, R. J.: Earthquake time series analysis by Cantor set model in Taiwan, Terr. Atmos. Ocean. Sci., 14, 85-98, 2003.

Chiapello, I., Bergametti, G., Gomes, L., Chatenet, B., Dulac, F., Pimenta, J., and Suares, E. S.: An additional low layer transport of Sahelian and Saharan dust over the north-eastern Tropical Atlantic, Geophys. Res. Lett., 22, 3191-3194, 1995.

Clauset, A., Shalizi, C. R., and Newman, M. E. J.: Power-law distributions in empirical data, SIAM Rev., 51, 661-703, 2009.

Criado, C. and Dorta, P.: An unusual "blood rain" over the Canary Islands (Spain). The Storm of January 1999, J. Arid Environ., 55, 765-783, 2002.

Custodio, E.: Aquifer overexploitation: What does it mean?, Hydrogeol. J., 10, 254-277, 2002.

De, U. S., Khole, M., and Dandekar, M. M.: Natural Hazards Associated with Meteorological Extreme Events, Nat. Hazards, 31, 487-497, 2004.

de Lima, M. I. P. and de Lima, J. L. M. P.: Investigating the multifractality of point precipitation in the Madeira archipelago, Nonlin. Processes Geophys., 16, 299-311, doi:10.5194/npg-16-2992009, 2009.

De Longueville, F., Hountondji, Y. C., Henry, S., and Ozer, P.: What do we know about effects of desert dust on air quality and human health in West Africa compared to other regions?, Sci. Total Environ., 409, 1-8, 2010.

De Longueville, F., Hountondjib, Y. C., Ozer, P., Marticorenad, B., Chatenetde, B., and Henrya, S.: Saharan Dust Impacts on Air Quality: What Are the Potential Health Risks in West Africa?, Hum. Ecol. Risk Assess., 19, 1595-1617, doi:10.1080/10807039.2012.716684, 2012.

De Longueville, F., Ozer, P., Doumbia, S., and Henry, S.: Desert dust impacts on human health: an alarming worldwide reality and a need for studies in West Africa, Int. J. Biometeorol., 57, 1-19, 2013.

Dialmeida, G. A.: A model for Saharan Dust Transport, J. Clim. Appl. Meteorol., 25, 903-916, 1986.

Díaz, J. P., Expósito, F. J., Torres, C. J., Herrera, F., Prospero, J. M., and Romero, M. C.: Radiative properties of aerosols in Saharan dust outbreaks using ground-based and satellite date: Applications to radiative forcing, J. Geophys. Res., 106, 18403-18416, doi:10.1029/2001JD900020, 2001.

Dickman, R.: Fractal rain distributions and chaotic advection, Braz. J. Phys., 34, 337-346, 2004.

Dubois, J. and Cheminee, J. L.: Fractal analysis of eruptive activity of some basaltic volcanoes, J. Volcanol. Geoth. Res., 45, 197208, 1991.

Fernandopullé, D.: Climatic characteristics of the Canary Islands, in: Biogeography and Ecology in the Canary Islands, Springer Netherlands, 30, 185-206, 1976.

Fisher, M. C., Koenig, G. L., White, T. J., and Taylor, J. W.: Pathogenic Clones versus Environmentally Driven Population Increase: Analysis of an Epidemic of the Human Fungal
Pathogen Coccidiodes immitis, J. Clin. Microbiol., 38, 807-813, 2000.

Font Tullot, I.: El tiempo atmosférico en las islas Canarias, Servicio Meteorológico Nacional, Sección de Predicción, 1956 (in Spanish).

García-Herrera, R., Puyol, D. G., Martín, E. H., Presa, L. G., and Rodriguez, P. R.: Influence of the North Atlantic Oscillation on the Canary Islands Pecipitation, J. Climate, 14, 3889-3903, 2001.

García-Herrera, R., Gallego, D., Hernández, E., Gimeno, L., Ribera, P., and Calvo, N.: Precipitation trends in the Canary Islands, Int. J. Climatol., 23, 235-241, doi:10.1002/joc.870, 2003.

Goudie, A. S.: Dust storms: Recent developments, J. Environ. Manage., 90, 89-94, 2009.

Goudie, A. S. and Middleton, N. J.: Saharan dust storms: nature and consequences, Earth Sci. Rev., 56, 179-204, 2001.

Goudie, A. S. and Middleton, N.: Desert dust in the global system, edited by: Czeschlik, D., Springer Berling Heidelberg New York, Heidelberg, 2006.

Heinold, B., Helmert, J., Hellmuth, O., Wolke, R., Ansmann, A., Marticorena, B., Laurent, B., and Tegen, I.: Regional modelling of Saharan dust events using LM-MUSCAT:Model description and case studies, J. Geophys. Res., 112, D11204, doi:10.1029/2006JD007443, 2007.

Holben, B. N., Tanré, D., Smirnov, A., Eck, T. F., Slutsker, I., Abuhassan, N., Newcomb, W. W., Schafer, J. S., Chatenet, B., Lavenu, F., Kaufman, Y. J., Vande Castle, J., Setzer, A., Markham, B., Clark, D., Frouin, R., Halthore, R., Karneli, A., O’Neill, N. T., Pietras, C., Pinker, R. T., Voss, K., and Zibordi, G.: An emerging ground-based aerosol climatology: Aerosol optical depth from AERONET, J. Geophys. Res., 106, 1206712097, 2001.

Izzo, M., Aucelli, P. P. C., and Mazzarella, A.: Recent changes in rainfalland air temperature at Agnone (Molise - Central Italy), Ann. Geophys.-Italy, 47, 1689-1698, doi:10.4401/ag3368, 2004.

Jankowiak, I. and Tanré, D.: Satellite climatology of Saharan dust outbreaks: Method and preliminary results, J. Climate, 5, 646656, 1992.

Juan, C., Emerson, B. C., Oromí, P., and Hewitt, G. M.: Colonization and diversification: towards a phylogeographic synthesis for the Canary Islands, Trends Ecol. Evol., 15, 104-109, doi:10.1016/j.bbr.2011.03.031, 2000.

Julià-Serdà, G., Cabrera, P., Acosta, O., Martín, P., Batista, J., Álamo, F., Rodríguez de Castro, F., and Antó, J. M.: High prevalence of asthma symptoms in the Canary Islands: climatic influence?, J. Asthma, 42, 507-511, 2005.

Karyampudi, V. M., Palm, S. P., Reagen, J. A., Fang, H., Grant, W. B., Hoff, R. M., Moulin, C., Pierce, H. F., Torres, O., Browell, E. V., and Melfi, S. H.: Validation of the Saharan dust plume conceptual model using Lidar, Meteosat, and ECMWF data, B. Am. Meteorol. Soc., 80, 1045-1076, 1999.

Kaufman, Y. J., Tanré, D., and Boucher, O.: A satellite view of aerosols in the climate system, Nature, 419, 215-223, 2002.

Laherrère, J. and Sornette, D.: Stretched exponential distributions in Nature and Economy: "fat tails" with characteristic scales, Eur. Phys. J. B, 2, 525-539, 1998.

Lerner, J. A., Westphal, D., and Reid, J.: Quality controlled surface visibility observations used to validate predicted surface 
aerosol concentration for southwest Asia, 20th Conference on Weather Analysis and Forecasting/16th Conference on Numerical Weather Prediction, Seattle, WA, 10-15 January 2004.

Levin, Z. and Cotton, W. R. (Eds.): Aerosol pollution impact on precipitation: a scientific review, Springer, Springer Science+Business Media B.V., Netherlands, 2009.

Liu, X., Yin, Z. Y., Zhang, X., and Yang, X.: Analyses of the spring dust storm frequency of northern China in relation to antecedent and concurrent wind, precipitation, vegetation, and soil moisture conditions, J. Geophys. Res., 109, D16210, doi:10.1029/2004JD004615, 2004.

Lovejoy, S., Schertzer, D., and Tsonis, A. A.: Functional boxcounting and multiple elliptical dimensions in rain, Science, 235, 1036-1038, 1987.

Lynn, B., Khain, A., Rosenfeld, D., and Woodley, W. L.: Effects of aerosols on precipitation from orographic clouds, J. Geophys. Res., 112, D10225, doi:10.1029/2006JD007537, 2007.

Mahowald, N. M., Baker, A. R., Bergametti, G., Brooks, N., Duce, R. A., Jickells, T. D., Kubilay, N., Prospero, J. M., and Tegen, I.: Atmospheric global dust cycle and iron inputs to the ocean, Global Biogeochem. Cy., 19, GB4025, doi:10.1029/2004GB002402, 2005.

Malamud, B. D. and Turcotte, D. L.: The applicability of power-law frequency statistics to floods, J. Hydrol., 322, 168-180, 2006.

Mandelbrot, B. B.: The fractal geometry of nature, W. H. Freeman and Co., New York, USA, 1983.

Martín, J. L., Bethencourt, J., and Cuevas, E.: Assessment of global warming on the island of Tenerife, Canary Islands (Spain). Trends in minimum, maximum and mean temperatures since 1944, Climatic Change, 114, 343-355, 2012.

Mayer, L.: Fractal characteristics of desert storm sequences and implications for geomorphic studies, Geomorphology, 5, 167-183, 1992.

Mazzarella, A.: Multifractal dynamic rainfall processes in Italy, Theor. Appl. Climatol., 63, 73-78, 1999.

Mazzarella, A. and Diodato, N.: The alluvial events in the last two centuries at Sarno, southern Italy: their classification and timepower law occurrence, Theor. Appl. Climatol., 72, 75-84, 2002.

Mazzarella, A. and Giuliacci, A.: The El Niño events: their classification and scale-invariance laws, Ann. Geophys.-Italy, 52, 517$522,2009$.

Mazzarella, A. and Rapetti, F.: Scale-invariance in the recurrence interval of extreme floods: an application to the Upper Po River valley (Northern Italy), J. Hydrol., 288, 264-271, 2004.

McTainsh, G. and Strong, C.: The role of aeolian dust in ecosystems, Geomorphology, 89, 39-54, 2007.

Mitzenmacher, M.: A Brief History of Generative Models for Power Law and Lognormal Distributions, Internet Mathematics, 1, 226251, doi:10.1080/15427951.2004.10129088, 2003.

Newman, M. E. J., Barabási, A.-L., and Watts, D. J.: The Structure and Dynamics of Networks, Princeton University Press, Princeton, New Jersey, 2006.

Olsson, J., Niemczynowicz, J., Berndtsson, R., and Larson, M.: An analysis of the rainfall time structure by box-counting - some practical applications, J. Hydrol., 137, 261-277, 1992.

Olsson, J., Niemczynowicz, J., and Berndtsson R.: Fractal Analysis of High-Resolution Rainfall Time Series, J. Geophys. Res., 98, 23265-23274, 1993.
Pelletier, J. D.: Cantor set model of eolian dust deposits on desert alluvial fan terraces, Geology, 35, 439-442, 2007.

Potter, T. D. and Colman, B. R. (Eds.): Handbook of weather, climate, and water: Atmospheric chemistry, hydrology, and societal impacts, Wiley-Interscience, Michigan, USA, 2003.

Prospero, J. M. and Lamb, J. P.: African droughts and dust transport to the Caribbean: Climate change and implications, Science, 302, 1024-1027, 2003.

Puyol, D. G., Herrera, R. G., Martín, E. H., Presa, L. G., and Rodríguez, P.: Major influences on precipitation in the Canary Islands, Climatic Change: Implications for the Hydrological Cycle and for Water Management, Adv. Glob. Change Res., 10, 57-73, 2002.

Sánchez-Lerma, B., Morales-Chirivella, F. J., Peñuelas, I., Blanco Guerra, C., Mesa Lugo, F., Aguinaga-Ontoso, I., and GuillénGrima, F.: High prevalence of asthma and allergic diseases in children aged 6 to 7 years from the Canary Islands: the International Study of Asthma and Allergies in Childhood, J. Invest. Allerg. Clin., 19, 383-390, 2009.

Sassen, K., DeMott, P. J., Prospero, J. M., and Poellot, M. R.: Saharan dust storms and indirect aerosol effects on clouds: CRYSTAL-FACE results, Geophys. Res. Lett., 30, 1633, doi:10.1029/2003GL017371, 2003.

Schertzer, D., Tchiguirinskaia, I., Lovejoy, S., and Tuck, A. F.: Quasi-geostrophic turbulence and generalized scale invariance, a theoretical reply, Atmos. Chem. Phys., 12, 327-336, doi:10.5194/acp-12-327-2012, 2012.

Schroeder, M.: Fractals, chaos, power laws: Minutes from an infinite paradise, W. H. Freeman Co., New York, USA, 1991.

Shi, Z. B., Woodhouse, M. T., Carslaw, K. S., Krom, M. D., Mann, G. W., Baker, A. R., Savov, I., Fones, G. R., Brooks, B., Drake, N., Jickells, T. D., and Benning, L. G.: Minor effect of physical size sorting on iron solubility of transported mineral dust, Atmos. Chem. Phys., 11, 8459-8469, doi:10.5194/acp-11-84592011, 2011.

Slingo, A., Ackerman, T. P., Allan, R. P., Kassianov, E. I., McFarlane, S. A., Robinson, G. J., Barnard, J. C., Miller, M. A., Harries, J. E., Russell, J. E., and Dewitte, S.: Observation of the impact of a major Saharan dust storm on the atmospheric radiation balance, Geophys. Res. Lett., 33, L24817, doi:10.1029/2006GL027869, 2006.

Smalley, R. F., Chatelain, J. L. Turcotte, D. L., and Prévot, R.: A fractal approach to the clustering of earthquakes: applications to the seismicity of the New Hebrides, B. Seismol. Soc. Am., 77, 1368-1381, 1987.

Sornette, D.: Critical phenomena in natural sciences: Chaos, fractals, self-organization, and disorder: Concepts and tools, 2nd Edn., Springer Series in Synergetics, Springer-Verlag, Heidelberg, 2004.

Sperling, F. N., Washington, R., and Whittaker, R. J.: Future climatic change of the subtropical North Atlantic: implications for the cloud forests of Tenerife, Climatic Change, 65, 103-123, 2004.

Stumpf, M. P. H. and Porter, M. A.: Critical truths about power laws, Science, 335, 665-666, doi:10.1126/science.1216142, 2012.

Suchodoletz, H., Glaser, B., Thrippleton, T., Broder, T., Zang, U., Eigenmann, R., Kopp, B., Reichert, M., and Ludwig, Z.: The influence of Saharan dust deposits on La Palma soil properties (Canary Islands, Spain), Catena, 103, 44-52, 2013. 
Takayasu, H.: Fractals in the Physical Science, Manchester University Press, New York, 1990.

Tsallis, C.: Introduction to nonextensive statistical mechanics: Approaching a complex world, Springer, New York, 2009.

Turcotte, D. L.: Fractals and chaos in geology and geophysics, Cambridge University Press, New York, 1997.

Veza, J. M.: Desalination in the Canary Islands: an update, Desalination, 133, 259-270, 2001.

Viana, M., Querol, X., Alastuey, A., Cuevas, E., and Rodríguez, S.: Influence of African dust on the levels of atmospheric particulates in the Canary Islands air quality monitoring network, Atmos. Environ., 36, 5861-5875, 2002.

Virkar, Y. and Clauset, A.: Power-law distributions in binned empirical data, pre-print, available at: http://arxiv.org/abs/1208.3524, last access: 26 February 2013, 2012.

Wauben, W. M.: Comparison of Visibility Measurements with Routine Visual Observations in The Netherlands, in: 3rd International Conference on Experiences with Automatic Weather Stations, Torremolinos, Spain, 2003.

West, G. B., Brown, J. H., and Enquist, B. J.: A general model for the origin of allometric scaling laws in biology, Science, 276, 122-126, doi:10.1126/science.276.5309.122, 1997.
Westphal, D. L., Toon, O. B., and Carlson, T. N.: A case study of mobilization and transport of Saharan dust, J. Atmos. Sci., 45, 2145-2175, 1988.

White, E. P., Enquist, B. J., and Green, J. L.: On estimating the exponent of power-law frequency distributions, Ecology, 89, 905912, 2008.

WMO (World Meteorological Organization): Manual on Codes, Suppl. 6 (VIII.2007), WMO, Geneva, Switzerland, 1995.

Yoon, Y. J., Ceburnis, D., Cavalli, F., Jourdan, O., Putaud, J. P., Facchini, M. C., Decesari, S., Fuzzi, S., Sellegri, K., Jennings, S. G., and O'Dowd, C. D.: Seasonal characteristics of the physicochemical properties of North Atlantic marine atmospheric aerosols, J. Geophys. Res., 112, D4206, doi:10.1029/2005J007044, 2007.

Zachow, C., Berg, C., Müller, H., Meincke, R., Komon-Zelazowska, M., Druzhinina, I. S., Kubicek, C. P., and Berg, G.: Fungal biodiversity in the soils/rhizospheres of Tenerife (Canary Islands): Relationship to vegetation zones and environmental factors, ISME J., 3, 79-92, 2008. 